\title{
PARASITES AND HELICOBACTER PYLORI IN EGYPTIAN CHILDREN WITH OR WITHOUT DIABETES WITH GASTROINTESTINAL MANIFESTATIONS AND HIGH CALPROTECTIN LEVEL By

\author{
HANAA I. RADY ${ }^{1 *}$, ALY ELKAZAZZ1', ENAS A. EL SAFTAWY2**, \\ and NOHA M. ABDELRAZEK ${ }^{2}$
}

Department of Pediatrics ${ }^{1}$ and Department of Medical Parasitology ${ }^{2}$, Faculty of Medicine, Cairo University, Egypt ( ${ }^{*}$ Correspondence:hanaaarady@gmail.com,

${ }^{* *}$ enas.ali.omar@kasralainny.edu.eg)

\section{Abstract}

This study highlighted the prevalence of parasitic infection in type-1 diabetes mellitus children and evaluated the effect of intestinal parasites on fecal calprotectin as a part of innate mucosal immunity. A total of 431 children with gastrointestinal manifestations attended the outpatients clinics, Aboul-Reesh Pediatric Teaching Hospital, Cairo University were randomly selected. Medical sheets were filled out on each patient. Stool samples were collected in labeled covered cartoon boxes and macroscopically examined for adult worms and segments, and microscopically for ova and protozoa by Lugol's iodine1\% smears and formol-ether concentration method, also, MZN was used for Cryptosporidium oocysts. Besides, stool samples were examined for Helicobacter pylori.

The results showed that 171/431 (39.67\%) were type-1DM (p=0.000) and $260(60.32 \%)$ were nondiabetic used as positive control. The overall intestinal parasitosis was $(45.26 \%), H$. pylori was $(39.47 \%)$, irritable bowel syndrome was $(25.78 \%)$, inflammatory bowel disease was $(3.96 \%)$. Treatment of the causative agents diminished the gastrointestinal troubles.

Keywords: Children, diabetes mellitus type 1, Intestinal parasitosis, Helicobacter pylori, Irritable bowel syndrome, Calprotectin.

\section{Introduction}

Diabetes mellitus is the most prevalent metabolic disorder worldwide (WHO, 2016), and the same encountered in Egypt (El-Tawdy et al, 2016). However, gastrointestinal parasites create benign diseases, and induce complications with high morbidity and mortality in the immunocompromised, including diabetic patients (El-nadi et al, 2015). Also, diabetes mellitus type 1 was associated with an increased prevalence of H. pylori, which contributed to autoimmune thyroiditis pathogenesis (Zekry and Abd Elwahid, 2013), strong association in diabetic retinopathy, neuropathy and nephronpathy (Agrawal et al, 2010) as well as gastrointestinal diseases (Tsay and Hsu, 2018).

Berni et al. (2004) reported that the fecal calprotectin in diagnosis and assessment of IBD was not fully defined. The positive fecal calprotectin test supported diagnosis or confirmed relapse of inflammatory in pediatric patients, but a negative one did not exclude bowel disease (Kostakis et al, 2013).

The study aimed to evaluate the role of the intestinal parasites with or without Heliobacter pylori in children with or without diabetes and gastrointestinal disorders.

\section{Materials and Methods}

Total of 413 children (215 males \& 245 females) were with diabetes mellitus Type 1 (190) and 260 without diabetes. All children were outpatients attending the clinics at Aboul-Reesh Pediatric Teaching Cairo University Hospital from May 2016 to December 2017.

Patients' ages ranged from 4 to 12 years. They suffered from gastro-intestinal disorders (GIDs) in the form of abdominal colic, fatigues, loss of weight, diarrhea altered with constipations. Some patients in Gastroenterology outpatient clinic were diagnosed as $H$. pylori infection, irritable bowel syndrome (IBS) and inflammatory bowel diseases (IBD). Diarrhea was defined by three or more loose or watery stools within $24 \mathrm{hrs}$. Demographic and clinical data were collected by questionnaires and patients' files. Children with Salmonella, Shigella, fungus, and /or endemic viral infections was excluded. 
Routine macroscopic and microscopic examination was done for three successive stool samples. Microscopic screening included direct wet smear stained with Lugol's iodine $1 \%$ and formol-ether concentration method. Modified $\mathrm{ZN}$ stain was used for Cryptosporidium oocysts.

The one site rapid test cassette (flow chromatographic immunoassay) of Cikbiotech detected the specific coproantigen for Helicobacter bacteria in stool samples.

Stool specimen was stabbed in at least different sites to collect 50mg of feces, and shacked to mix the specimen and the extraction buffer. Samples of Helicobacter antigen was developed two lines, for test and control (Montalto et al. 2010).

Fecal calprotectin was measured quantitatively (Radin et al, 2014). DRG: HYBRiDXL Calprotectin Kit, which is a solid phase sandwich ELISA (Calprest1, Eurospital, Trieste, Italy). Wells of reagent cartridges were antibody-coated ones. Murine monoclonal antibody captured an exclusive antigenic site in the chemical composition of the calprotectin molecule. Aliquots from the collected samples and enzyme conjugate were incubated together in the coated well. The used enzyme conjugate was a monoclonal anti- calprotectin antibody impregnated with horse-radish peroxidase enzyme. Wells were washed off to remove unbound conjugate. Bound peroxidase conjugate amount was measured by color intensity. Calprotectin concentration measure higher than $200 \mu \mathrm{g} / \mathrm{g}$ was considered positive.

The Ethical Committee of Cairo University was followed and written informed agreement was obtained from the parents of the participated patients who joined.

\section{Results}

The E. histolytica/dispar, G. lamblia, B. hominis, $C$. parvum infections significantly differed among two groups. H. pylori was only significant with $G$. lamblia $(\mathrm{P}<0.05)$. Among DM patients the intestinal parasitosis was $45.26 \%$, but $H$. pylori were $39.47 \%$. DM status was significantly associated with increased prevalence of intestinal parasitic infections. The fecal calprotectin was significantly associated $(\mathrm{p}<0.05)$ with $C$. parvum $10(52.63 \%)$, G. lamblia $10(45.45 \%)$ and $H$. pylori infection $40(21.62 \%)$. Analysis showed strong significant relationship between the gastrointestinal disorders and E. histolyticaldispar, $H$. nana, C. parvum infections, and $H$. pylori $(\mathrm{P}<0.05)$. Details were given in tables $(1,2,3,4 \& 5)$.

Table 1: Intestinal parasites among diabetic and non-diabetic patients

\begin{tabular}{|l|c|c|c|c|c|c|c|}
\hline Type of parasite & \multicolumn{2}{|c|}{ Positive } & \multicolumn{2}{c|}{ DM } & \multicolumn{2}{c|}{ Non-DM } & \multirow{2}{*}{ P value } \\
\hline Entamoeba histolytica/dispar & Count & $\%$ & count & $\%$ & count & $\%$ & \\
\hline Giardia lamblia & 20 & 4.84 & 13 & 7.43 & 7 & 2.94 & 0.035 \\
\hline Blastocystis hominis & 22 & 5.33 & 18 & 10.29 & 4 & 1.68 & $<0.001$ \\
\hline Hymenolepis nana & 35 & 8.47 & 16 & 9.14 & 9 & 3.78 & 0.023 \\
\hline Ascaris lumbricoides & 10 & 2.42 & 6 & 3.43 & 4 & 1.68 & 0.335 \\
\hline Cryptosporidium parvum & 4 & 0.97 & 1 & 0.57 & 4 & 1.68 & 0.402 \\
\hline Parasite free & 19 & 4.60 & 17 & 9.71 & 2 & 0.84 & $<0.001$ \\
\hline Total & 303 & 73.37 & 104 & 59.43 & 208 & 87.39 & $<0.001$ \\
\hline
\end{tabular}

Table 2: Helicobacter pylori positive cases among patients with intestinal parasites

\begin{tabular}{|l|c|c|c|c|c|}
\hline Type of parasite & \multicolumn{2}{|c|}{ Positive } & \multicolumn{2}{c|}{ H. pylori +ve } & P value \\
\hline E. histolytica /dispar & 20 & $4.84 \%$ & 10 & $6.21 \%$ & 0.409 \\
\hline G. lamblia & 22 & $5.33 \%$ & 17 & $10.56 \%$ & $<0.001$ \\
\hline B. hominis & 35 & $8.47 \%$ & 15 & $9.32 \%$ & 0.827 \\
\hline H. nana & 10 & $2.42 \%$ & 2 & $1.24 \%$ & 0.209 \\
\hline A. lumbricoides & 4 & $0.97 \%$ & 3 & $1.86 \%$ & 0.310 \\
\hline C. parvum & 19 & $4.60 \%$ & 9 & $5.59 \%$ & 0.571 \\
\hline Parasite free & 303 & $73.37 \%$ & 105 & $65.22 \%$ & $<0.001$ \\
\hline Total & 413 & 100.00 & 161 & 41.11 & --- \\
\hline
\end{tabular}


Table 3: Relation between diabetes mellitus with or without parasitic infection

\begin{tabular}{|c|c|c|c|c|c|c|c|c|c|c|}
\hline \multirow{2}{*}{ Infective agent } & \multicolumn{2}{|c|}{ Positive } & \multicolumn{2}{|c|}{$\mathrm{DM}$} & \multicolumn{2}{|c|}{ Non DM } & \multirow{2}{*}{$\begin{array}{c}\text { P val- } \\
\text { ue }\end{array}$} & \multirow{2}{*}{ OR } & \multicolumn{2}{|c|}{$95 \% \mathrm{CI}$} \\
\hline & No. & $\%$ & No. & $\%$ & No. & $\%$ & & & Lower & Upper \\
\hline With parasites & 147 & 32.67 & 86 & 45.26 & 52 & 20.00 & \multirow{2}{*}{$<0.001$} & \multirow{2}{*}{3.308} & \multirow{2}{*}{2.180} & \multirow{2}{*}{5.019} \\
\hline No parasites & 303 & 67.33 & 104 & 54.74 & 208 & 80.00 & & & & \\
\hline H. pylori & 185 & 41.11 & 75 & 39.47 & 110 & 42.31 & \multirow{2}{*}{0.546} & \multirow{2}{*}{0.889} & \multirow{2}{*}{0.608} & \multirow{2}{*}{1.302} \\
\hline No H. pylori & 265 & 58.89 & 115 & 60.53 & 150 & 57.69 & & & & \\
\hline
\end{tabular}

Table 4: Relation between fecal calprotectin and parasitic infection

\begin{tabular}{|l|c|c|c|c|}
\hline \multicolumn{1}{|c|}{ Infective agent } & Total & \multicolumn{2}{|c|}{ Fecal calprotectin positive (above $200 \mu \mathrm{g} / \mathrm{g})$} & P value \\
\hline E. histolytica /dispar & 20 & 3 & $15.00 \%$ & 0.736 \\
\hline G. lamblia & 22 & 10 & $45.45 \%$ & $<0.001$ \\
\hline B. hominis & 35 & 2 & $5.71 \%$ & 0.293 \\
\hline H. nana & 10 & 1 & $10.00 \%$ & 1 \\
\hline A. lumbricoides & 4 & 0 & $0.00 \%$ & 1 \\
\hline C. parvum & 19 & 10 & $52.63 \%$ & $<0.001$ \\
\hline Parasite free & 266 & 30 & $11.28 \%$ & 0.004 \\
\hline H. pylori & 185 & 40 & $21.62 \%$ & \multirow{2}{*}{0.001} \\
\cline { 1 - 4 } No pylori & 265 & 19 & $7.17 \%$ & \\
\cline { 1 - 3 }
\end{tabular}

Table 5: Frequencies of protozoan parasites and gastro-intestinal disorders

\begin{tabular}{|c|c|c|c|c|c|c|c|c|c|}
\hline \multirow[t]{2}{*}{ Type of parasite } & \multicolumn{2}{|c|}{ Total } & \multicolumn{2}{|c|}{ IBS } & \multicolumn{2}{|c|}{ IBD } & \multicolumn{2}{|c|}{ Normal or other } & \multirow{2}{*}{$P$ value } \\
\hline & No. & $\%$ & No. & $\%$ & No. & $\%$ & No. & $\%$ & \\
\hline $\begin{array}{l}\text { E. histolyti- } \\
\text { ca/dispar }\end{array}$ & 20 & 4.84 & 5 & 25.00 & 2 & 10 & 13 & 65.00 & $<0.001$ \\
\hline G. lamblia & 22 & 5.33 & 15 & 68.18 & 3 & 13.64 & 4 & 18.18 & $<0.001$ \\
\hline B. hominis & 35 & 8.47 & 13 & 37.14 & 3 & 8.57 & 19 & 54.29 & 0.272 \\
\hline H. nana & 10 & 2.42 & 4 & 40.00 & 4 & 40 & 2 & 20.00 & 0.003 \\
\hline A. lumbricoides & 4 & 0.97 & 3 & 75.00 & 0 & 0 & 1 & 25.00 & 0.106 \\
\hline C. parvum & 19 & 4.60 & 0 & 0.00 & 10 & 52.63 & 9 & 47.37 & $<0.001$ \\
\hline Parasite free & 303 & 73.37 & 70 & 23.10 & 12 & 3.96 & 221 & 72.94 & $<0.001$ \\
\hline Total & 413 & 100 & 110 & 26.63 & 34 & 8.23 & 269 & 65.13 & --- \\
\hline H. pylori & 185 & 41.11 & 66 & 35.68 & 25 & 13.51 & 94 & 50.81 & \multirow{2}{*}{$<0.001$} \\
\hline No H. pylori & 265 & 58.89 & 50 & 18.87 & 20 & 7.55 & 195 & 73.58 & \\
\hline Total & 413 & 100 & 110 & 26.63 & 34 & 8.23 & 289 & 64.22 & --- \\
\hline
\end{tabular}

\section{Discussion}

In the present study, comprehensive fecal examination among children with gastrointestinal manifestations showed that the overall intestinal parasites in diabetic children was $(45.26 \%)$ compared to $(20 \%)$ in nondiabetic ones. In the diabetic children (type 1), E. histolytica/dispar (7.43\%), G. lamblia $(10.29 \%) B$. hominis $(9.14 \%) H$. nana (3.43\%) A. lumbricoides $(0.57 \%)$ and $C$. parvum $(9.71 \%)$ compared to $2.94 \%, 1.68 \%$, $3.78 \%, 1.68 \%, 1.68 \%$, \& $0.84 \%$ respectively. The overall $H$. pylori positive cases were (65.22\%), with high associated with $G$. lamblia (10.56\%), followed by B. hominis (9.32\%), E. histolytica/dispar (6.21\%), C. parvum $(5.59 \%)$, A. lumbricoides (1.86\%). and lastly $H$. nana (1.24\%). Association be- tween DM-type1 and parasitosis was due to tendency of diabetes to exacerbate anemic by diminishing the erythropoietin production (Mohtashamipour et al, 2015), particularly when associated with the low personal hygiene (Khan and Tisman, 2010). Consequently, the innate and adaptive immune responses together with the reduced intestinal motility in diabetic patients fail to resolve intestinal parasitosis (Knapp, 2013). Establishment of a regulatory network contributes to control of overt immune responses to allow longer survival of the parasite while restricting inflammation that might otherwise lead to pathology (Elliott and Weinstock, 2017). Alterations in the host immune state might influence and be affected by other concomitant disease(s) (Liu et al, 
2010). Fecal calprotectin and inflammatory biomarker respond to any unspecific nature to various gastrointestinal conditions, high values were recorded in $C$. parvum and $G$. lamblia infections (Radin et al, 2014). But, helminthes as $H$. nana and Ascaris recorded high calprotectin levels that described by the masterful immune regulation exerted by regulatory $\mathrm{T}$ cells, alternatively activated by macrophages in luminal helminthes (Cordeiro-da-Silva, et al, 2014). No doubt, undiagnosed intestinal parasitic infections led to confliction bet- ween functional (IBS) and organic bowel (IBD) disorders (Pohl et al. 2013). Ascaris lumbricoides produce antienzymes, which stand beyond increased excretion of fats, nitrogenous compounds and lactose (Duque et al. 1972), G. lamblia trophozoites damage the upper villus of small intestine (Solomons, 1982), where lactase enzyme is highly expressed (Vahedi, et al, 2012). Moreover, G. lamblia were associated with lower ferritin levels in anemic children without significant associations as to residence and/or body mass index (Atwa and Thabet, 2016). Cryptosporidiosis was the cause of risky diarrhea in children (Shalaby and Shalaby, 2015)

In the present study, 185 patients $(41.11 \%)$ were $H$. pylori positive; (42.31\%) among non-diabetic children compared to $(39.47 \%)$ in diabetic children. Diagnosis of $H$. pylori antigen by immune-chromatography proved highly dependable and sensitive (Andersen et al, 1995). Also, H. pylori and G. intestinalis were reported among organic causes of recurrent abdominal pain, with different prevalence mainly in developing countries as common associated diseases causing agents (Eldash et al, 2013). Consequently, the early diagnosis helped patients to escape chronic gastritis complications (Sigthorsson et al. 2001), and progression into painful stomach ulcers due to excessive release of gastrin hormone and loss of blood (Gulcelik et al. 2005). No doubt, the poor glycemic control, autonomic neuropathy and impaired cellular and humoral immunity supported $H$. pylori colonization (Bener et al, 2007). Mohammad et al. (2008) reported that not only that the $H$. pylori infection was extremely higher among Egyptian schoolchildren, but also its' adverse effects was far beyond the stomach.

Thus, treatment of the inflammatory bowel disorder with steroids as anti-inflammatory agents, expose these children to the side effects of the drug. Drawbacks encompass bad control of glucose homeostasis and aggravation of the immunity weakness (Asseldonk et al. 2012). Steroids exert immunomodulation on T \& B cells; affect the size of lymphoid organs and lymphocyte cell death (Coutinho and Chapman, 2011). This action worsens both the child diabetic status of and aggravates the opportunity of some parasites (Dave et al. 2014). Moreover, diabetes mellitus is a metabolic disorder with abnormally high level of blood glucose makes diabetics to be considered as immune-compromised individuals. Two types of intestinal parasites are helminthes and protozoa are important causes of infections in immuno-compromised individuals (Nazligul et al, 2001).

The inflammation that can be observed as (IBD) be either organic or inorganic type (Kaser et al, 2010). Additionally, irritable bowel syndrome (IBS) resembles somehow clinically IBD which is also considered as the second health problem to GIT. IBS is a highly prevalent gastrointestinal disorder of the unknown origin (Wilson and Crabtree, 2007). IBD is a disease of unknown cause associated with diarrhea and colonic lesions that are identified by endoscopy (Kaya $\boldsymbol{e t} \boldsymbol{a l}$, 2005). The etiology of each one is varying and may involve some microbial agents such as invasive Entamoeba histolytica that causes ulceration of the mucosa of the large intestine. (Friedman and Blumberg, 2008)

In diabetic infants the hyperglycemic environment, gastrointestinal dysmotility and immune dysfunction including neutrophil damage, depression of the antioxidant system and humoral immunity favor gastrointestinal infections. Intestinal parasitic infections play a crucial deceiving role by being 
the intermittent in their nature of excretion (Munns et al, 2016).

\section{Conclusion}

Intestinal parasitic infections were high in diabetic children than in non-diabetic ones.

$H$. pylori co-infection with intestinal parasites was highly prevalent. Pathogenicity of intestinal parasites induce symptoms mimic irritable bowel syndrome. Intestinal protozoans induce fecal calprotectin while intestinal helminthes evade innate mucosal immunity. Parasites infection and $H$. pylori must be considered with low hygiene style and impaired immunity as diabetic children. Symptoms related to some parasites mimic irritable bowel syndrome due to their intercalated pathogenesis. Protozoan infections and $H$. pylori may induce high calprotectin values. The low values of fecal calprotectin in intestinal helminthes were a model for immune evasion. Confusing parasitic causes that induce high calprotectin values with IBD may expose children to immune compromising treatment, especially those with type-1 DM. Children treatment will be published in due time by the first author.

\section{Recommendations}

Generally, Intestinal parasites usually create benign diseases, though they may induce complications with high morbidity and mortality to the immune-compromised patients, particularly diabetic and handicapped children. Children with or without diabetes who have gastrointestinal disorders may be presented with varying behavioral manifestations.

Thus, the proper diagnosis and specific treatment of them are indicated particularly in diabetic ones to avoid risky complications

\section{Acknowledgments}

The authors would like to thank the Staff Authorities at Aboul-Reech Children's Hospital, Cairo University, especially the ICU and Laboratory Teams and all patients and their parents for cooperation and sincerity during the study period.

Confliction of interest: Authors have neither interest nor received financial support.
Contribution of authors: Hanaa I. Rady: Administrative, technical, and material support, clinical aspects, treatment, and mastering the study, Aly Elkazazz: Study concept and design; Drafting of the manuscript. E.A.EL Saftawy: Analysis and interpretation of data, Noha M Abdelrazek: Revision of the manuscript for important intellectual content; Statistical analysis

\section{References}

Agrawal, RP, Sharma, R, Garg, D, Pokharna, R, Kochar, DK, et al, 2010: Role of Helicobacter pylori in causation of diabetic gastropathies and non-gastrointestinal complications in type 2 diabetes. J. Indian Med. Assoc. 108, 3:140-3.

Andersen, LP, Espersen, F, Souckova, A, et al, 1995: Isolation and preliminary evaluation of a low molecular (LMW) antigen preparation for improved detection of Helicobacter pylori $\mathrm{IgG}$ antibodies. Diag. Lab. Immunol. 2:156-9.

Asseldonk, DP, Seinen, ML, de Boer, NK, van -Bodegraven, AA, Mulder, CJ, 2012: Hepatotoxicity associated with 6-methyl mercaptopurine formation during azathioprine and 6-mercaptopurine therapy does not occur on the shortterm during 6-thioguanine therapy in IBD treatment. Crohns Colitis 6:95-101.

Atwa, ZTH, Thabet, MM, 2016: Intestinal parasitic infection in egyptian children: Could it be a risk factor for iron deficiency anemia? J. Egypt. Soc. Parasitol. 46, 3:533-40.

Bener, A, Micallef, R, Derbala, M, Al-Mulla, H, Usmani, M, 2007: Association between type 2 diabetes mellitus and helicobacter pylori infection. Turk. J. Gastroenterol. 18, 4: 225-9.

Cordeiro-da-Silva, A, Laforge, M, Ouaissi, A, Akharid, K, Silvestre, R, et al, 2014: Impairment of T Cell Function in Parasitic Infections. PLoS Negl. Trop. Dis. 8, 2:e2567.

Coutinho, A, Chapman, KE, 2011: The antiinflammatory and immunosuppressive effects of glucocorticoids, recent developments and mechanistic insights. Mol. Cell Endocrinol. 335, 1:213.

Dave, M, Purohit, T, Razonable, R, Loftus, J R, 2014: Opportunistic infections due to inflammatory bowel disease therapy. Inflamm. Bowel Dis. 20:196-212.

Duque, TK, Bolaños, O, Lotero, H, Mayoral, LG, 1972: Malabsorption syndrome in ascariasis. Am. J. Clin. Nutr. 25, 11:1276-81. 
Eldash, HH, Bekhit, OE, Algameel, AA, 2013: Impact of Helicobacter pylori-giardiasis coinfection on children with recurrent abdominal pain. J. Egypt. Soc. Parasitol. 43, 2:509-16.

Elnadi, NA, Hassanien, HA, Ahmad, AM, Abd-Ellah, AK, 2015: Intestinal parasites in diabetic patients in Sohag University Hospitals, Egypt. J. Egypt. Soc. Parasitol. 45, 2:43-9

El-Tawdy, AHF, Ibrahim, EA, Abdallah, ES, Morsy, TA, 2016: Screening for the diabetes mellitus: General information for patients to avoid foot amputation. EMMJ 71, 1:61-74.

Friedman, S, Blumberg, R, 2008: Inflammatory bowel disease. In: Harrison's Principles of Internal Medicine. McGraw-Hill Publications.

Elliott, DE, Weinstock, JV, 2017: Nematodes and human therapeutic trials for inflammatory disease. Parasite Immunol. 39, 5:e12407.

Gulcelik, NE, Kaya, E, Demirbas, B, et al, 2005: Helicobacter pylori prevalence in diabetic patients and its relationship with dyspepsia and autonomic neuropathy. J. Endocrinol. Invest. 28: 214-7.

Liu, Z, Liu, Q, Bleich, D, Salgame, P, Gause, W, 2010: Regulation of type 1 diabetes, tuberculosis, and asthma by parasites. J. Mol. Med. 88, 1:27-38.

Kaser, A, Zeissig, S, Blumberg, RS, 2010: Inflammatory bowel disease. Ann. Rev. Immunol. 28:573-621.

Kaya, E, Gulcelik, NE, Demirbas, B, et al, 2005: Helicobacter pylori prevalence in diabetic patients and its relationship with dyspepsia and autonomic neuropathy. J. Endocrinol. Invest. 28, 3: \214-7.

Khan, Y, Tisman, G, 2010: Pica in iron deficiency: A case series. J. Med. Case Report 4:8690.

Knapp, S, 2013: Diabetes and infection: Is there a link? A mini-review. Gerontol. 59, 2:99-104.

Kostakis, ID, Cholidou, KG, Vaiopoulos, AG, Vlachos, IS, Perrea, D, et al, 2013: Fecal calprotectin in pediatric inflammatory bowel disease: a systematic review. Dig. Dis. Sci. 58, 2: 309-19.

Mohammad, MA, Hussein, L, Coward, A, Jackson, SJ, 2008: Prevalence of Helicobacter pylori infection among Egyptian children: Impact of social background and effect on growth. Publ. Hlth. Nutr. 11, 3:230-6.

Mohtashamipour, M, Hoseini, G, Pestehchian, N, Yousefi, H, Fallah, E, et al, 2015: Intes- tinal parasitic infections in patients with diabetes mellitus: A case-control study. J. Anal. Res. Clin. Med. 3, 3:157-63.

Montalto, M, Gallo, A, Ianiro, G, Santoro, L, D'Onofrio, F, et al, 2010: Can chronic gastritis cause an increase in fecal calprotectin concentrations? World J. Gastroenterol. 16, 27:3406-10.

Munns, CF, Shaw, N, Kiely, M, Specker, BL, Thacher, TD, et al, 2016: Global consensus recommendations on prevention and management of nutritional rickets. J. Clin. Endocrinol. Metab. 101, 2:394-8.

Nazligul, Y, Sabuncu, T, Ozbilge, H, 2001: Is there a predisposition to intestinal parasitosis in diabetic patients? Diabetes Care 24: 1503-4.

Pohl, D, Frühauf, H, Fried, M, Vavricka, S R, Fox, M, et al, 2013: Lactose malabsorption and intolerance: pathogenesis, diagnosis and treatment. United Euro Gastroenterol. J. 1, 3:151-9. Radin, JN, Gaddy, JA, Loh, JT, Piazuelo, M B, Kehl-Fie, TE, et al, 2014: The host protein calprotectin modulates the Helicobacter pylori cag-Type iv secretion system via zinc sequestration. PLoS Pathog. 10, 10:e1004450.

Shalaby, NM, Shalaby, NM, 2015: Cryptosporidium parvum infection among Egyptian school children. J. Egypt. Soc. Parasitol. 45, 1:125-31.

Sigthorsson, G, Tibble, J, Foster, R, Sherwood, R, Fagerhol, M, et al, 2001: Fecal calprotectin and fecal occult blood tests in the diagnosis of colorectal carcinoma and adenoma. Gut 3: $402-8$.

Solomons, NW, 1982: Giardiasis: Nutritional implications. Rev. Infect. Dis. 4, 4:859-69.

Tsay, FW, Hsu, PI, 2018: H. pylori infection \& extra-gastroduodenal diseases. J. Biomed. Sci. 25, 1:65-9.

Vahedi, M, Gohardehi, S, Sharif, M, Daryani, A, 2012: Prevalence of parasites in patients with gastroenteritis at East of Mazandaran Province, Northern Iran. Trop. Biomed. 29, 4:568-74.

WHO, 2016: Global Report on Diabetes: website (http://www.who.int)

Wilson, KT, Crabtree, JE, 2007: Immunology of Helicobacter pylori: Insights into the failure of the immune response and perspectives on vaccine studies. Gastroentrol. 133, 1:288-308.

Zekry, OA, Abd Elwahid, HA, 2013: The association between Helicobacter pylori infection, type 1 diabetes mellitus, and autoimmune thyroiditis. J. Egypt. Publ. Hlth. Assoc. 88, 3:143-7. 